\title{
VI. Regrouping Social Identities
}

\author{
Abigail J. STEWART and Alyssa N. ZUCKER
}

What is profoundly satisfying and exciting about this paper is that it successfully argues for direct linkages between large-scale, macro-level social structures and individual psychology. It does this by examining how intergroup and intragroup processes work, at least as they create a psychology of subordinates. (There are some implications for the psychology of dominants here, but they are somewhat less fully worked out.) This kind of argument is rare in psychology, although Apfelbaum reminds us that it is hardly absent. Our deep pleasure at re-encountering this paper is tempered by our awareness that this argument, like others that have aimed at this kind of linkage, remains woefully marginal or forgotten in the discipline of psychology.

The US context creates an exaggerated focus on the individual throughout the social science disciplines that aim to understand behavior. Psychology goes further to focus not only on individuals, but on universal aspects of them (such as perceptual and cognitive capacities and personality traits). As a result, social history (including the impact of social history on particular birth cohorts), social forces (such as economic transformations) and the distribution of power between groups are largely seen as outside the purview of psychologists. As Apfelbaum notes, psychologists have been concerned about 'harmful and pathogenic effects' of social phenomena, but this concern has been expressed in a focus on therapeutic, rather than social, solutions. The argument in 'Relations of Domination and Movements of Liberation' provides a remarkably comprehensive and generative theoretical framework in which to place certain research programs in psychology. We believe that although these research programs have produced significant understanding, placing them within Apfelbaum's framework would

Feminism \& Psychology (C) 1999 SAGE (London, Thousand Oaks and New Delhi), Vol. 9(3): 296-299.

[0959-3535(199908)9:3;296-299;009265] 
both permit more powerful interpretations of existing findings, and allow us to ask important new questions.

Apfelbaum's account identifies several specific effects of the process of 'degrouping', or breaking down a group's sense of itself as a group. Two of these have been subject to substantial amounts of research in psychology and in organizational behavior: the study of 'tokens' (see, for example, Cohen and Swim, 1995; Gutek and Morasch, 1982; Kanter, 1977; Wolman and Frank, 1975; Yoder, 1991, 1994) and the study of people's belief in certain allegedly 'universal rules' (for example, in a 'just world'; see Furnham and Procter, 1989; Lerner and Miller, 1978; Lipkus and Bissonnette, 1996; O'Connor et al., 1996). Early research on tokens examined the effects of being a token on the token, with little or no attention to the effects of the token process on others who share that social status (but are not themselves tokens). Apfelbaum's perspective enables us to shift from the individual token to the meaning of the mere existence of tokens for others in the subordinate, or even in the dominant, group. If we consider the token as a phenomenon specific to degrouping a subordinate group, we would expect being a solo group representative in a small group context to differ in its effects for the token and for others within or outside the small group if that solo individual represents a dominant versus a subordinate group. If that individual represents a subordinate group, being a token is part of a set of processes that isolate group members from the support and affirmation that comes from group identification. In contrast, if a solo represents a dominant group, being a token might well simply reinforce the hegemony of the dominant group.

The same sort of clarity is gained if we draw on Apfelbaum to consider the literature on individuals' endorsement of belief in a 'just world', or in the fairness of universal rules (or of rules that challenge universal rules, like affirmative action). Here, Apfelbaum's framework would force us to examine how individuals' positions within dominant and subordinate groups alter the meaning of their endorsement (or challenge) of universal rules. Thus, when members of dominant groups endorse universal rules, they express their own identification with a system in which they are privileged. When, in contrast, members of subordinate groups endorse those rules, they are expressing a belief that requires their own lack of access to a supportive group identification. With this perspective in mind, it would be impossible to view endorsement of these views as 'individual differences'; we would have to examine the differential implications of one's own and one's observation of others' endorsement of those beliefs for members of different groups.

We have found that Apfelbaum's theoretical account provides similar illumination in a field much closer to home for us. Our own work together focuses on issues of social identity, specifically women's identification with their own gender, racial/ethnic and class groups (Henderson-King and Stewart, 1994, 1997). In previous research, we have explored the implications of these identifications for women's psychological well-being (e.g. Ostrove et al., under review), but especially for their political socialization (Cole and Stewart, 1996; Cole et al., 
1998; Stewart et al., 1998). Apfelbaum's notion that identification with a subordinate group (women, various subordinated racial/ethnic groups, etc.) is the basis for 'regrouping' strikes us as particularly useful in thinking about the functions and consequences of social identities, and for recognizing that subordinate social identities are crucially different from dominant ones (see the developing literature on 'whiteness', e.g. Fine et al., 1997).

In our current research we are examining identification with feminism (a 'regrouped' identification with women) in different generations. Scholars of feminism in a number of academic disciplines, as well as in the popular press, have noted the paradox that although younger generations have become increasingly liberal in their gender attitudes, they seem to have become less willing to identify themselves as feminists (Buschman and Lenart, 1996; Griffin, 1989; Kamen, 1991). The popular phrase, 'I'm not a feminist, but . . ' signifies many women's reluctance to take on the label or identity 'feminist', despite the fact that they publicly espouse at least some feminist beliefs. We suspect that such women, who lack group identification, will be much less likely to engage in collective action on behalf of women than women who hold similar beliefs but do adopt the label (identify with the group). To understand this problem, we studied three groups of women in three generations: feminists, who believe in equal rights for women and consciously adopt the label 'feminist'; egalitarians, who believe in equal rights for women but reject the label 'feminist'; and non-feminists, who reject both equal rights for women and the label 'feminist'. Among these groups of women, we were able to examine implications of feminist identity for commitment to social change and engagement in political action.

Like other scholars in the social identity tradition, we have focused on the behavioral and personal consequences of belonging to the group 'feminists', rather than on specific processes and power relations that press individuals to 'degroup' (or lose identification with the group) and the factors which enable others to 'regroup'. Using Apfelbaum's framework would lead us to look, for example, at the processes of tokenism and universal rules to understand the differences between feminists and egalitarians. For example, feminist and egalitarian women may both believe that there are few ability or essential differences between men and women, but only egalitarians should endorse universal rules (as permitting them to get ahead, for example) or view tokens favorably (as evidence that individual women, through hard work, can get ahead). In contrast, feminists should reject universal rules (e.g. belief in meritocracy) and endorse some ideas that challenge them (such as affirmative action). Similarly, they should be suspicious of token processes, whether they affect them directly or other women. In a related manner, feminists and egalitarians should differ in attitudes and values reflecting regrouping (with feminists affected by regrouping in ways egalitarians are not). Thus, feminists should attach greater value than egalitarians to evidence of women's cultural and historical achievements. It may also be possible to use Apfelbaum's framework to help understand non-feminists' attitudes. For example, non-feminists may be satisfied with the status quo, and therefore 
oblivious to the effects of degrouping. In contrast, egalitarians recognize the effects of degrouping (in women's lesser cultural value and isolation), but see universal rules and token processes as obviating the need for regrouping.

While we have a clear personal stake in mining Apfelbaum's theorizing for our own work, we are equally struck by its value not only for understanding psychological phenomena, but for understanding the recent history of feminist theory. It is useful, we think, to view both 1970s 'cultural feminism' and later 'difference feminism' arguments as part of a process of regrouping, or responding to a prior degrouping. Similarly, recognizing the need for groups to 'pool grievances' as a basis for regrouping sheds new light on the energy provided by consciousness-raising in the 1970s, and the potency of accounts of women's vulnerability to domestic violence, incest and sexual assault. At the same time, Apfelbaum's framework may help us understand certain conflicts and debates in feminism. For example, the urgency of the need for regrouping helps account for the centrality of identity politics in contemporary feminist theorizing, as well as for the debate about whether it is time to abandon a feminism grounded in a recognition of women as 'victims'.

We do not mean to suggest that Apfelbaum's framework, as articulated in the paper reproduced in this volume, provides a full and complete guide to our own or others' work on social identities. Important theoretical work remains to be done. For example, the contemporary articulation of notions of multiple, potentially conflicting (subordinate) identities, as well as of intersectionality (or the unique identities created by the intersection of different dominant and subordinate identities), requires elaboration of Apfelbaum's account in this paper. Equally, for our own developing work on activism across difference (whites committed to antiracist activism, male feminists, straights in gay-straight alliances, etc.), we need to understand more about the conditions under which members of dominant groups act outside of identification with their group. Here, as usual, we view Apfelbaum as providing a wonderful starting point. She allows us to rephrase our questions: Why do some members of dominant groups notice and object to degrouping of other groups? Why do some members of dominant groups encourage and support regrouping of other groups? Asking the questions in this way helps. But there is clearly more work to be done. Apfelbaum reminds us that the process of 'refinding a buried history' gives strength to regrouping. There is much in her work to strengthen and sustain feminist psychologists; we must work, though, to keep it from being buried.

ADDRESS: Abigail J. STEWART and Alyssa N. ZUCKER, University of Michigan, Department of Psychology, 525 East University Avenue, Ann Arbor, MI 48109-1109, USA. 